\title{
INVEST
}

INVEST Working Papers 38/2021

\section{Adolescent Social Capital - An Intergenerational Resource?}

Minna Tuominen

Jenni Tikkanen

27.10.2021

ISSN 2737-0534 
The Inequalities, Interventions, and New Welfare State (INVEST) aims at increasing wellbeing of Finnish society during childhood, youth and early adulthood and preventing psychosocial risks compromising such development through innovative interventions. Based on cutting-edge research on the conditions and mechanisms involved at different periods of development, INVEST will evaluate and develop various universal and targeted interventions to improve the efficiency of the current welfare state institutions at critical points of the early life course. INVEST aims at providing a new model for the welfare states that is more equal, better targeted to problem groups, more anticipatory as well as economically and socially sustainable. INVEST is a Flagship project of the Academy of Finland. 


\section{Adolescent Social Capital - An Intergenerational Resource?}

Minna Tuominen (corresponding author)

INVEST Research Flagship Center

University of Turku

Assistentinkatu 7

20014 Turku, Finland

Jenni Tikkanen

Turku Institute for Advanced Studies and the Department of Education

University of Turku

Assistentinkatu 5

20014 University of Turku, Finland

This work was supported by the Finnish Cultural Foundation [one-year individual grant awarded to the first author] and the Academy of Finland's Flagship Programme [Decision number: 320162]. 


\title{
Adolescent Social Capital - An Intergenerational Resource?
}

\begin{abstract}
Introduction: Social capital is a valuable asset that spawns multiple benefits, but little is known about its origins. This study narrows the gap by exploring the extent to which adolescents' social capital is shaped by their parents' social capital, the socioeconomic status (SES) of their families, or that of their neighbourhood. The study also explores which dimensions of adolescent social capital are most sensitive to intergenerational or socioeconomic influence.
\end{abstract}

Methods: The study uses cross-sectional survey data gathered from adolescents aged $12-13$ years and their parents $(\mathrm{n}=167)$ in Southwest Finland. For the analysis, adolescents' social capital was disaggregated into four dimensions: social networks, social trust, tendency to receive help, and tendency to provide help. For each dimension, the associations with the hypothesised predictors were analysed separately using structural equation modelling.

Results: The results suggest that parents' social capital is the most influential predictor to each dimension of adolescents' social capital establishing stronger associations as compared to the other two predictors. However, it is not the parents' actual social capital as they report themselves, but their offspring's perception of their social behaviour. Family's SES relates to young people's reciprocal tendency and level of trust but only indirectly through parents' social capital. Conversely, a disadvantaged socioeconomic neighbourhood is directly negatively associated with adolescents' level of trust and frequency of receiving help. 
Conclusions: This study suggests that social capital is distinctly, although not exclusively, an intergenerational resource. Parents are critical role models for adolescent children.

Keywords: social capital, social networks, trust, reciprocity, intergenerational transmission, socioeconomic status 


\section{Adolescent Social Capital - An Intergenerational Resource?}

\section{Introduction}

Social capital (SC) is a valuable asset that spawns multiple benefits, such as better school performance (e.g. Lindfors et al., 2018), enhanced health status (e.g. Novak et al., 2018), and higher level of well-being (e.g. Ferguson, 2006; Tuominen \& Haanpää, 2021). Despite ample research in this field, little is known about the origins of SC. Some authors claim it accrues among the better-off (e.g. Kouvo, 2010; Lin, 2001; Pichler \& Wallace, 2009), but there is not much empirical evidence of this phenomenon. Even less attention has been paid to the potential intergenerational transmission of SC.

In this study, we narrow this gap by exploring the extent to which SC is transferred from one generation to the next. We also study how socioeconomic context may affect SC accumulation. For this purpose, we have gathered survey data from adolescents aged 12-13 years, and their parents.

During the passage from childhood to adolescence, relationships expand beyond the family circuit (Choudhury et al., 2006), and trust, trustworthiness, and prosocial and reciprocal behaviours towards other people increase (Fett et al., 2014a. See also Fett et al. 2014b; Padilla-Walker et al., 2018; Stolle \& Hooghe, 2004; Sutter \& Kocher, 2007). This is the result of an increasing capacity to take into account other persons' perspectives (Fett et al., 2014b). Strengthened prosocial behaviour towards friends and strangers is also explained by increased intimacy and time spent with friends, as children mature (Carlo, 2006; in Padilla-Walker et al 2018). After adolescence, some of 
these characteristics, such as the level of social trust remains largely stable through adulthood (Stolle \& Hooghe, 2004).

\section{Theoretical Framework}

\section{Social Capital and its Dimensions}

Despite decades of research on SC, the elusiveness of the concept, and the lack of theoretical purity have impeded the accumulation of evidence (Engbers et al., 2017). We rely on Pierre Bourdieu's and Robert Putnam's texts, which can be considered complementary views on individual-level SC (Tuominen \& Haanpää, 2021). Conceptually, Putnam expanded Bourdieu's definition of SC from social networks and reciprocity, or 'exchange' of gifts/favours as Bourdieu referred to it (Bourdieu, 1986), to also include trust in other people (Putnam, 2000, p. 19). We adopt this expanded definition and explore the potential intergenerational and socioeconomic origins of each of them simultaneously. To the best of our knowledge, this is the first study of its kind.

Inspired by Mark Granovetter's theory (1973) on strong ties and weak ties, Putnam distinguishes between bonding and bridging SC. The former comprises exclusive relationships involving family and close friends (i.e., strong ties), whereas the latter refers to more inclusive relationships with more distant acquaintances (weak ties) (Putnam, 2000, pp. 22-23). Because of the young age of the group we are interested in, we assume they do not yet have extensive bridging SC. Nevertheless, in our analysis, we go beyond the strongest family ties and focus also on the somewhat weaker ties with friends, peers, and neighbours.

\section{Influence of Parents}

According to social learning theory, social interaction is a practice learned in early childhood. Parents open their own social networks to their children. As part of the 
socialisation process, primary caretakers also pass their values, perspectives, and examples onto their offspring, mainly through role modelling and verbal persuasion (Bandura, 1982). When a child is still learning verbal communication, socialisation relies more on physical examples; verbal socialisation becomes more central as the child grows older (Bandura, 2017, p. 54; Moen et al., 1997; Stolle \& Nishikawa, 2011).

The closer the parent-child relationship, the stronger the effect of socialisation (Padilla-Walker et al., 2018; Weiss, 2012). As mothers still act as the primary attachment figures in most cases, their role is particularly critical, for instance, in prosocial behaviour (Padilla-Walker et al., 2018) and social trust (Nomaguchi et al., 2011; Rotenberg, 1995). However, fathers' role likely increases throughout adolescence years (Rotenberg, 1995).

To our knowledge, the only previous study on the intergenerational transmission of SC was conducted by Harald Weiss (2012), who found a significant association between middle- and high-school students' (mean age 16 years) social networks, and that of their parents. Weiss suggests that the intensity of parents' participation in organised social activities influences the standard with which their offspring proportionate their level of participation (Weiss, 2012). However, Weiss' analysis only considers the social network dimension of SC. Based on social learning theory, we hypothesise that the dimensions of trust and reciprocity are likewise intergenerationally transmitted (H1).

\section{Influence of Family's Socioeconomic Status}

Bourdieu argues that social class background, which we conceptualize here as socioeconomic status (SES), largely defines how people behave. This is because of habitus, the durable way of being shaped by one's socioeconomic status. Similar life 
histories and living conditions of a given social class form a standardising norm, which orients the behaviour and practices of that group (Bourdieu, 1990, pp. 53-59). Habitus is thus a learned way of being, the foundation of which is laid in childhood through the socialisation process (Bourdieu, 2005; Bourdieu \& Wacquant, 1995, p. 165).

Instead of studying the link between SES and SC, most researchers have focused on the negative impact of poverty/material deprivation on social relationships. Jan Jonsson and Carina Mood have identified three mechanisms that may explain this effect: (i) economic hardship implies limited means to cover the costs of social life (outings, membership fees, trips, birthday presents, etc.), thereby reducing one's possibility of participation; (ii) economic challenges may affect self-esteem and generate a sense of shame, compelling people to withdraw from social interactions; (iii) consciously or unconsciously, other people may avoid involving those who are known to face economic challenges, to save them from the embarrassment of not being able to afford the same things as others. (Jonsson \& Mood, 2014, pp. 324-325). Yet, it is not the absolute economic conditions that matter, but to have possibilities similar to those of one's peers (Hjalmarsson \& Mood, 2015).

Childhood poverty may also have a long-lasting influence on the level of social trust. Trust implies investing resources ahead of time and reaping the benefits later. This involves some level of uncertainty about the returns. Life-history theory suggests that a childhood home marked by resource scarcity spawns life strategies that prioritise fast returns of any investment to limit the risk of missing out a reward. Therefore, children in low-income families often exhibit lower levels of social trust (Stamos et al., 2019).

Economic stress may also affect prosocial behaviour. However, the results are inconclusive regarding the direction of the effect. Some authors claim that economic 
stress reduces the tendency to help others (Davis \& Carlo, 2019), while others suggest that people who experience hardships may demonstrate heightened sensitivity towards the hardships of others (McGinley et al., 2010).

The scarcity of literature on the effects of SES on adolescent SC leaves the discussion open. In the present study, we hypothesise that SES relates to every dimension of the adolescents' SC (H2). Likewise, we expect SES to simultaneously associate with parents' SC.

\section{Influence of Neighbourhood}

According to James Laurence (2019), in disadvantaged neighbourhoods, young people have fewer positive social interactions, more frequent negative interactions, and lower levels of trust amongst neighbours. Positive relationships require trust that other people are generally well-intentioned (Coleman \& Hoffer, 1987; Putnam, 2000; Ross et al., 2001). Mistrust is common in neighbourhoods populated by people who have fewer resources and where disorder, vandalism, and poor maintenance of public places are widespread (Ross et al., 2001).

According to social disorganisation theory (Sampson \& Groves, 1989), structural characteristics, such as residential mobility, ethnic heterogeneity, family disruption, and poverty, reduce social control in a community (Elliott et al., 1996; Sampson, 2012; Valdimarsdóttir \& Bernburg, 2015). Reduced social control loosens the connections between people and decreases their involvement in joint activities (Veysey \& Messner, 1999, p. 157). James Coleman understands social control as the expression of a collective SC. He asserts that a community where parents know their children's friends and the parents of those friends, form an "intergenerational closure", which is key for maintaining social control. In such closure, parents can jointly agree upon the 
set of rules they collectively impose on their offspring (Coleman, 1988; Coleman \& Hoffer, 1987). Some studies have found evidence supporting Coleman's proposition; in communities where parents know each other, adolescents are more committed to schoolwork and are less often involved in delinquent behaviour (Valdimarsdóttir \& Bernburg, 2015).

Most research on neighbourhood effects has focused on the highly stratified US society. The social landscape looks rather different in Europe, particularly in the more egalitarian Northern Europe, with extensive welfare systems and high levels of social trust (Pichler \& Wallace, 2009). While there are disadvantaged neighbourhoods in Northern Europe as well, the differences between the upper and lower ends of the socioeconomic ladder are less extreme, even if the gap has widened over the past decades (Erola, 2010). Therefore, we hypothesise that in the Nordic context, neighbourhoods' socioeconomic status affects adolescent social relationships, social trust, and reciprocity, but the effect sizes are small (H3).

\section{Present Study}

The purpose of the present study is to assess whether and to what extent SC is an intergenerational resource, that is, a resource that passes over from parents to their children. The study also examines the extent to which the socioeconomic context in which children grow up is associated with their SC. More specifically, the study seeks to answer the following research questions:

(RQ1) To what extent can social capital be considered an intergenerational resource?;

(RQ2) To what extent is young people's social capital associated with the family's socioeconomic context?; 
(RQ3) To what extent is social capital associated with the socioeconomic context of the neighbourhood in which adolescents grow?; and

(RQ4) Which dimensions of adolescent social capital, if any, are the most sensitive to intergenerational and socioeconomic influence?

\section{Materials and methods}

\section{Participants and Procedure}

This study uses the cross-sectional survey Social capital of children and adults 2018. The survey was conducted in 2018 among sixth-grade comprehensive school students (mean age 12.47 years) and their parents or legal guardians in four municipalities in Southwest Finland ${ }^{1}$. Of the 62 comprehensive schools, 21 (34\%) agreed to take part in the study ${ }^{2}$. In these schools, 494 of 626 students (79\%) were authorised by their parents to participate in the survey, and $464(94 \%)$ consented themselves to participate. ${ }^{3}$ At the same time, 170 parents $(37 \%)$ responded to a questionnaire specifically addressing them.

This study utilises a sub-sample of 167 students who met two criteria: their parents participated in the study; and they had studied at the same school for at least the past two school years. The latter criterion is important for two reasons. First, schools are vital locations where young people build their social networks, and a change in school may cause a significant interruption in this process. Second, to build an indicator for

${ }^{1}$ Municipalities of Turku, Kaarina, Parainen, and Raisio.

${ }^{2}$ Over the past decade, Finland's compulsory school system has triggered much interest nationally and internationally, and schools have been subjected to an increasing amount of research. To protect their educational goals, many schools nowadays limit their participation only to the compulsory surveys carried out by the Ministry of Education and Culture. Therefore, the relatively low proportion of participating schools was somewhat expected.

${ }^{3}$ The survey plan was previously reviewed and approved by the Ethical Review Board of the researchers' host institution and by municipal education authorities. 
neighbourhood socioeconomic status, we matched the postal code of the schools with the official postal code area statistics of Statistics Finland, which are from the year 2017 (i.e., one year before our data were collected). In Finland, the vast majority of compulsory school students attend neighbourhood schools, which are public schools situated in the areas where they live. Therefore, the area surrounding the school typically equals the students' living area as long as they have not changed schools.

Questionnaires were designed to capture comparable information from the adolescents and their parents. The questionnaires included commonly used SC indicators related to respondents' strong and weak networks (e.g. with family, friends, hobby networks, neighbours, and, in the case of adolescents, schoolmates, and school personnel), the frequency of interaction with and the level of trust in the members of the networks, as well as the propensity to provide help to and receive help from the network members (i.e., reciprocal behaviour).

The parents' questionnaire served as the basis for the subsequent formulation of the students' questionnaire. Special attention was paid to adjusting the language and content of the questions to suit the young age group. The students' questionnaire was pre-tested among fifth graders (i.e., one year younger students than the target group) to ensure trouble-free comprehension of the instrument. Students completed the questionnaire during school hours with guidance provided by either a teacher or the first author. The student questionnaire was available both online and in paper format, while the parents' questionnaire was only available online. Parents participated in the study in their own time, following the instructions included in the questionnaire. 


\section{Measures and Data Analyses}

Data on adolescent SC came directly from the students' survey. Information on parents' SC came from two sources: directly from the parents' survey, and indirectly from the students' survey who also reported on their parents' social behaviour or sociability, as they perceived it.

The analysis builds on factors measuring: (1) adolescents' SC, (2) parents' SC, and (3) adolescents' perception of their parents' sociability, as well as separately calculated factor scores of families' SES and neighbourhood socioeconomic disadvantage. Two sets of confirmatory factor analysis (CFA) were conducted to examine the factor structure and validity of the measures of adolescents' and parents' SC. In the CFA models, residual errors were initially assumed to be uncorrelated, and the factors were allowed to correlate. In the next step, these specifications were somewhat adjusted, as explained in next sections. Internal consistencies for the scales of the latent factor scores were further examined using Cronbach's alpha (Field, 2009). Due to the restriction caused by the ratio of the sample size to the number of free parameters (Kline, 2011), the factor scores of the two CFA models were saved and used as 'observed' variables in the SEM model.

The hypothesised connections $(\mathrm{H} 1-\mathrm{H} 3)$ were tested using structural equation modelling (SEM). The analyses were carried out on Mplus 8.4 with a maximum likelihood estimator with robust standard errors (MLR) due to the sample size (Muthén \& Muthén, 2006) ${ }^{4}$. Regarding normality, the univariate distributions of the research variables were within a reasonable range (skewness \pm 2 , kurtosis \pm 7 ) (Curran et al.,

\footnotetext{
${ }^{4}$ There were few missing data on some observed variables (0.6-3.0\% per item), which were dealt with full information maximum likelihood.
} 
1996), except for two variables ${ }^{5}$. The variables included in the factors were measured on ordinal scales, ${ }^{6}$ but are treated here as continuous variables.

The fit of the CFA and SEM models was evaluated by the chi-square test statistic and fit indices, including root mean square error of approximation (RMSEA), standardised root mean square residual (SRMR), Tucker Lewis index (TLI), and comparative fit index (CFI). The following cut-off values were used: RMSEA and SRMR values under .08 (Hair et al., 2010; Hu \& Bentler, 1998) and TLI and CFI values close to or greater than .90 (Bentler, 1992; Hair et al., 2010) indicate a suitable and well-fitting model. As the chi-square test statistic is very sensitive to the sample size, we consider the ratio of the chi-square value to the degrees of freedom $\left(\chi^{2} / \mathrm{df}<2\right)$ rather than the mere significance of the test result (Byrne, 2012; Hu \& Bentler, 1995).

\section{Adolescents' Social Capital}

The data did not fit well with the initially hypothesised three-factor (networks, trust, reciprocity) CFA-model; therefore, adjustments were made. Based on the modification indices in Mplus, the dimensions of providing and receiving help were separated into two factors, one observed item was removed from the model because of strong cross-loadings, and one residual correlation was allowed (.32; SRH_2 and SPH_2 $)^{7}$. With these modifications, a good fit to the data was obtained: $\chi^{2}(47) 56.28, p$ .17 (scaling correction factor 1.13), RMSEA .03, SRMR .05, CFI .98, and TLI .97.

The latent factor items and standardised factor loadings of the final adolescents' SC CFA model are presented in Table 1 along with descriptive statistics. All

\footnotetext{
5 These items were 'Number of [student's] friends' (SSN_1; skewness -3.7; kurtosis 13.7), and 'How often [student] receives help from family when they have a problem' (SRH_1; - 2.3; 5.3).

${ }^{6}$ The variables were standardised to harmonise the differences in the original measurement scales.

7 This correlation is likely to results from a higher importance of reciprocity in friendship relationships in comparison to those with family members or classmates.
} 
Cronbach's alpha values were above the commonly used threshold of .60, except for the adolescents' social networks. Nevertheless, given that the scale reliability of the overall combined solution was relatively high (.78), the analysis was run with these configurations.

Table 1: Latent factor items, standardised factor loadings, and descriptive statistics of adolescents'social capital

\begin{tabular}{llllll}
\hline Item & Measurements & Factor & Range & $\boldsymbol{M}$ & $\boldsymbol{S D}$ \\
& & & & & \\
\hline SSN_1 & Hdolescents' social networks (alpha .50) & .28 & $1-4$ & 3.84 & .51 \\
SSN_2 & How often do you meet your friends outside school & .62 & $1-4$ & 3.27 & .81 \\
SSN_3 & How often do you spend time with other kids outside & .65 & $1-4$ & 3.20 & .87 \\
& Adolescents' trust in others (alpha .65) & & & & \\
SST_1 & To what extent do you feel you can trust your classmates & .73 & $1-5$ & 3.41 & .95 \\
SST_2 & To what extent do you feel you can trust your neighbours & .62 & $1-5$ & 2.71 & 1.02 \\
SST_3 & To what extent do you feel you can trust Finns in general & .50 & $1-5$ & 2.12 & 1.03 \\
& Adolescents' tendency of receiving help (alpha .64) & & & \\
SRH_1 If you encounter problems, your family tends to help you & .36 & $1-4$ & 3.75 & .55 \\
SRH_2 & If you encounter problems, your friends tend to help you & .64 & $1-4$ & 3.38 & .68 \\
SRH_3 & If you encounter problems, your classmates tend to help & .87 & $1-4$ & 3.13 .79 \\
& Adolescents' tendency of providing help (alpha .78) & & & \\
SPH_1 & If your family members encounter problems, you try to & .73 & $1-4$ & 3.56 & .65 \\
SPH_2 & If your friends encounter problems, you try to help & .71 & $1-4$ & 3.65 & .60 \\
SPH_3 & If your classmates encounter problems, you try to help & .78 & $1-4$ & 3.25 & .69 \\
\hline
\end{tabular}

$.28^{*}$, SSN with SRH $.35^{*}$, SSN with SPH $.32^{*}$, SST with STR $.64^{* * *}$, SST with SPH $.39^{* * * *}$, and SRH with SPH $.81^{* * *}\left({ }^{*} \mathrm{p}<.05 ;{ }^{* * *} \mathrm{p}<.001\right)$.

\section{Parents' Social Capital}

Two parallel approaches were employed to measure parents' SC: direct and indirect. The direct approach was based on parents' own reports on their social networks, trust in other people, and tendency to reciprocate; the indirect approach was based on adolescents' perceptions of their parents' sociability (see Table 2). For the former, a three-factor CFA model was designed. After allowing a residual correlation (.25) between two variables (PSN_5 and PSN_6), the model fit the data well: $\chi^{2}(40)$ 66.80, p .005 (scaling correction factor 1.00), RMSEA .06, SRMR .07, CFI 0.92, TLI 
0.89. For the latter, the survey included only three items (ref. Table 2) that were added

to the SEM model directly, as it was not possible to separately test the factor structure

without saturating the model.

Table 2: Items of latent factors of parental social capital (with standardised factor loadings), alpha values, and descriptive statistics

\begin{tabular}{|c|c|c|c|c|c|}
\hline Item & Measurements & Factor & Range & $M$ & $S D$ \\
\hline & $\begin{array}{l}\text { PARENT'S SOCIAL CAPITAL (alpha .70) } \\
\text { Parent's social networks (alpha .61) }\end{array}$ & & & & \\
\hline PSN_1 & How often do you participate in hobbies & .56 & $1-6$ & 4.43 & 1.77 \\
\hline PSN_2 & How often do you participate in voluntary work & .46 & $1-6$ & 2.22 & 1.55 \\
\hline PSN_3 & How often do you participate in associations' activities & .43 & $1-6$ & 2.48 & 1.56 \\
\hline PSN_4 & How often do you take part in courses outside work & .52 & $1-6$ & 2.99 & 1.42 \\
\hline PSN_5 & How often do you meet your friends & .36 & $1-7$ & 4.36 & 1.36 \\
\hline PSN_6 & $\begin{array}{l}\text { How many close, trusting relationships do you have } \\
\text { Parent's level of trust in others (alpha .83) }\end{array}$ & .33 & $1-7$ & 3.91 & 1.36 \\
\hline PST_1 & To what extent do you find people trustworthy & .78 & $1-10$ & 7.23 & 1.76 \\
\hline PST_2 & To what extent do you find people fair & .79 & $1-10$ & 7.69 & 1.76 \\
\hline PST_3 & $\begin{array}{l}\text { To what extent do you find people helpful } \\
\text { Parent's tendency of reciprocal behaviour (alpha .70) }\end{array}$ & .80 & $1-10$ & 7.07 & 1.62 \\
\hline PRB_1 & How often do you offer help to people who are close to & .64 & $0-6$ & 4.98 & .84 \\
\hline PRB_2 & How often do people who are close to you offer to help & .87 & $0-6$ & 4.74 & 1.08 \\
\hline & Parents' perceived sociability ${ }^{\dagger}$ (alpha .60) & & & & \\
\hline PPS_1 & How often do you chat with your parents about your & .65 & $1-3$ & 2.42 & .65 \\
\hline PPS_2 & How often do your parents chat with your friends & .66 & $1-3$ & 2.31 & .67 \\
\hline PPS_3 & How often do your parents chat with your friends' parents & .46 & $1-3$ & 1.91 & .73 \\
\hline
\end{tabular}

.19 , PST with PRB $.20\left({ }^{* * *} \mathrm{p}<.001\right) ;{ }^{\dagger}$ based on the student data

\section{Socioeconomic Status of Family}

Three variables were used to measure families' SES: parents' highest achieved level of education, parents' own subjective assessment of the adequacy of household income, and net monthly income equivalised to household size (see Table 3). The original level of household income was given using ten income brackets following the practice applied in, for example, the European Social Survey (ESS Round 6) (e.g., 1 695-2 070 euros, 2 071-2 479 euros, 2 480-2 986 euros etc.). Only the first and last scale points referred to the lowest and highest cut-off points (less than 1010 euros, at 
least 5361 euros) instead of a range. To obtain a computable income, a new variable was created where each income range was substituted with the mean value of the respective range. However, the respective cut-off point values were used for the lowest and highest income categories. Thus, the obtained new values for income were then divided by the squared number of household members to obtain the equivalent income level that is sensitive to household size and composition, following a practice also used, for instance, by the OECD (2019).

\section{Socioeconomic Disadvantage of Neighbourhood}

Publicly available postal code area statistics were used to define the socioeconomic status of the neighbourhoods where the participating schools were located. For this purpose, three variables were used: proportion of adult residents in the two lowest income deciles ${ }^{8}$, proportion of adult residents in the two highest income deciles $^{9}$ (reverse-coded), and the proportion of adult residents who were unemployed (see Table 3). Jointly, the three variables measure the level of socioeconomic disadvantage of the neighbourhood. The postal code area statistics refer to the year 2017, that is, one year before the present survey data were gathered. However, since neighbourhood socioeconomic profiles tend to change slowly, this is not considered problematic. Moreover, the sample comprised only adolescents who had not changed school within the past two years.

Table 3: Items of sum scores measuring family SES and neighbourhood socioeconomic profile, alpha values of the sum scores, and descriptive statistics per item

\begin{tabular}{llccc}
\hline Item & Measurements & Range & $\boldsymbol{M}$ & SD \\
\hline & Family socioeconomic status (alpha .71) & & & \\
SES_1 & Respondent's highest achieved education level & $1-14$ & 7.36 & 2.94 \\
SES_2 & Subjective assessment of the household income level & $1-4$ & 3.01 & 0.77
\end{tabular}

\footnotetext{
${ }^{8}$ Two lowest income deciles corresponds to people earning max 13287 euros/year.

${ }^{9}$ Two highest income deciles corresponds to people earning more than 31874 euros/year.
} 
SES_3 Equivalised per person gross monthly income (based on $\quad 451-3791 \quad 1888.7 \quad 655.60$

\begin{tabular}{|c|c|c|c|c|}
\hline & Neighbourhood socioeconomic profile ${ }^{\dagger}$ (alpha .92) & & & \\
\hline NSP_1 & $\%$ of adult population $(18+$ years $)$ in the postal code area & $12.28-32.38$ & 20.28 & 6.26 \\
\hline & whose annual income is within two lowest income deciles & & & \\
\hline NSP_2 & $\%$ of adult population $(18+$ years) in the postal code area & $9.36-29.23$ & 18.63 & 6.14 \\
\hline & whose annual income is within two highest income deciles & & & \\
\hline NSP_3 & $\%$ of adult population $(18+$ years $)$ who were unemployed & $5.02-24.03$ & 11.97 & 5.80 \\
\hline
\end{tabular}

\section{Results}

\section{Descriptive Results}

As presented in Table 1, adolescents' average scores are high for nearly all SC variables. Most of these variables are left-skewed, except for two trust-related variables. Likewise, the mean value of parents' SC is high on most (reported and perceived) measures, with the exception of network-related variables.

There was a moderate gender bias in the student sample (55\% of the respondents were girls), but the parents' sample was more strongly biased ( $84 \%$ were mothers). Less than $5 \%$ of the parents had only basic education, while $29 \%$ had a higher education degree. The average monthly income level in the sample was 1888.76 euros/person ${ }^{10}$. Only 5\% earned less than 750 euros/person, and 4\% received more than 2800 euros per person. Thus, the sample appears to be dominated by middle-class households.

According to the official postal code area statistics, in the neighbourhoods where our sample population lives and goes to school, one-fifth of the adult inhabitants have a yearly income corresponding to the lowest two income deciles in the country. At the same time, nearly another fifth belong to the highest two income deciles in the country.

\footnotetext{
${ }^{10}$ Total household income equivalised to household size.
} 
In these neighbourhoods, the average share of the unemployed people of all those available for the labour market is 11.97 percent, which is close to the national average of 11.30 percent (authors' calculations based on postal code area statistics, Statistics Finland). In light of these statistics, the sample adequately represents the overall Finnish socioeconomic gradient.

\section{Analytical Results}

According to the SEM analysis, the hypothesised model of adolescent SC fits well with the data: $\chi^{2}(34) 43.48$, p .13 (scaling correction factor 1.03); RMSEA .04; SRMR .05; CFI 0.99; TLI 0.97. As illustrated in Figure 1, the results support the hypotheses, but only partly. No direct connections were found between parents' reported SC dimensions and the respective adolescents' SC dimensions. However, there was a non-hypothesised path from parents (self-reported) social networks to parents' perceived sociability (as reported by adolescents), which, in turn, contributed significantly to all four dimensions of adolescents' SC in accordance with H1.

Contrary to H2, no direct association between family SES and adolescent SC was found. However, family SES was a direct predictor of all dimensions of parents' (direct and indirect) SC, and through parents' indirect SC it predicted adolescents' social trust and tendencies of receiving and giving help from/to others (see Table 4).

Lastly, as hypothesised (H3), the neighbourhood's socioeconomic disadvantage was found to be associated with adolescents' trust and their tendency to receive help from others, but no relationship was found with their social networks or provision of help.

According to these results, adolescents' propensity to receive help and place trust in others is related to all the predictors, although only indirectly to the families' 
SES. The tendency to provide help relates to parents' perceived sociability and indirectly to families' SES, but not to the neighbourhood context. Adolescents' social networks relate only to their parents' perceived sociability.

Figure 1: Structural model of adolescents' social capital with standardized coefficients and r-squared values

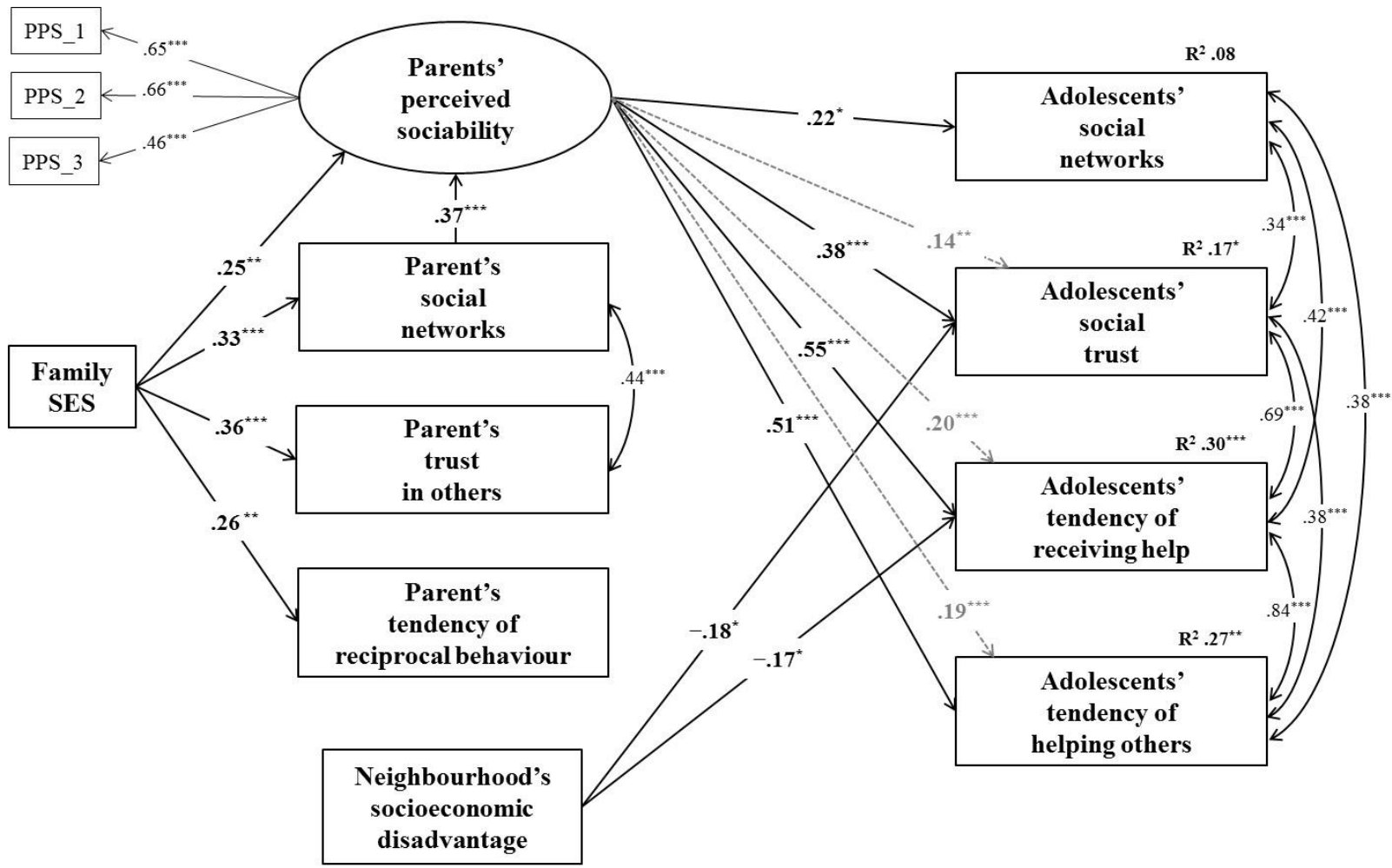

Only statistically significant paths depicted; indirect effects marked with dashed lines; " $\mathrm{p}<.05$;

${ }^{* *} \mathrm{p}<.01 ;{ }^{* * *} \mathrm{p}<.001$

Table 4: Standardised indirect effects of family's socioeconomic status

\section{Indirect effect}

Esti

Through parents' perceived sociability on

Adolescents' social networks

Adolescents' social trust

Adolescents' tendency of receiving help

Adolescents' tendency of helping others

Through parents' social networks and parents' perceived

Adolescents' social networks

Adolescents' social trust

Adolescents' tendency of receiving help 
Adolescents' tendency of helping others .06 Note: ${ }^{*} \mathrm{p}<.05 ;{ }^{* *} \mathrm{p}<.01 ;$ sum of indirect effects presented in Figure 1.

\section{Discussion}

This study delved into the origins of adolescent SC and assessed the extent to which it is shaped by parents' SC (RQ1), the socioeconomic status of their families (RQ2), and the socioeconomic disadvantage of their neighbourhood (RQ3). The study also explored which dimensions of SC are most sensitive to intergenerational or socioeconomic influence (RQ4). We disaggregated young people's SC into four dimensions - social networks, social trust, the tendency to receive help, and the tendency to provide help - and analysed the associations between the hypothesised predictors separately with each dimension. Using SEM modelling, we were able to assess these relationships simultaneously in the same model.

In our sample, both adolescents and their parents exhibited a high average level of SC. Of the three hypothesised predictors, our results suggest that parents' SC is the most influential; as hypothesised (H1), it relates to each dimension of adolescents' SC, and establishes stronger associations than the other two predictors. Hence, our study suggests that SC is distinctly, although not exclusively, an intergenerational resource. This is in line with earlier research (Weiss, 2012).

The results reveal an important detail in the intergenerational transmission of $\mathrm{SC}$; the key is not parents' de facto SC as they report themselves, but the perception that their offspring forms of their approach towards other people. The more the youngsters observe their parents to engage with others, the more they provide/receive support to/from other people, the stronger their trust in others, and the more frequent their interaction with people. This observation suggests that the intergenerational 
transmission of SC is to a large extent based on a learned behaviour; parents are critical role models for their adolescent children.

This finding is also interesting from a theoretical point of view. The indicators used to assess parents' perceived SC also form a measure of an intergenerational closure that James Coleman wrote about. Our results indicate that in communities where the parents know each other and each other's children, young people develop stronger social ties, higher levels of trust, and more intense reciprocal tendencies. Thus, it appears that the Putnamian SC may not be directly transmissible from one generation to another, but the density of intergenerational closure (i.e., the Colemanian type of SC) gives rise to the Putnamian type of SC.

Contrary to our research hypothesis 2 , the study found no evidence of a direct association between families' SES and adolescents' SC. Our results suggest, however, that families' SES is associated with parents' SC, and through this indirect path it affects young people's tendency to reciprocate and put trust in others. This finding follows Bourdieu's theory of habitus, the class-based way-of-being, which has been instilled in children through and by the parents since early childhood. It may happen that the association with family SES intensifies as the adolescents grow older. It is also possible that the effect of SES is more indirect than direct at every age.

The absence of direct association between families' SES and adolescents' SC may also be a consequence of the fact that the sample was dominated by middle-class families. It included only a few, if any, cases of substantial material deprivation, which according to Hjalmarsson and Mood (2015), is the most detrimental aspect for social relationships. Future research should shed more light to the relationship between family SES and adolescents' SC. 
The results provide partial support for research hypothesis 3: a disadvantaged socioeconomic context marked by a high level of unemployment and low level of income, is associated with a lower level of social trust and less frequent reception of help. Contrary to the findings of Laurence (2019), the present study did not find a relationship between neighbourhoods' socioeconomic disadvantage and young people's social networks. However, Laurence only considered neighbourhood characteristics and family SES, but not parents' SC, which may have introduced omitted variable bias (e.g. Wooldridge, 2018). Moreover, his research focused on older youth (16-17 years old), who undoubtedly spend more time in their neighbourhood, and consequently may be more influenced by the surrounding environment than younger adolescents.

In summary, while the directly measured dimensions of parents' SC did not contribute to adolescents' SC, parents' perceived sociability did. The more sociable the adolescents perceived their parents to be, the higher was their own SC. Furthermore, the more intense the parents' networks were, the higher was their sociability as perceived by the adolescents. The study also suggests that an increase in family's SES directly associates with a higher level of parental SC and thereby with a higher level of adolescents' SC. Lastly, the associations between the neighbourhood socioeconomic context and adolescents' SC are only weak and partial. Of the different dimensions of adolescent SC, reciprocal behaviour and trust in others appear the most sensitive to intergenerational or socioeconomic influence.

Previous research has shown that already in early adolescence, SC may contribute significantly to subjective well-being, overall health, and academic performance. The present study suggests that SC is to a large extent a learned resource; parents provide a powerful example. To support young people's wellbeing and positive 
development, home and school education should systematically strengthen young people's social networks, encourage their trust in other people, and accustom them in reciprocal practices. Some elements, such as social trust, are largely consolidated during the adolescent years (Stolle \& Hooghe, 2004). Therefore, early and systematic investment in SC buildings is likely to yield valuable development results later in life.

\section{Limitations}

Although our study provides important contributions to the literature, there are caveats that need to be considered. Our sample size $(n=167)$ was modest and only represented the southwestern region of Finland. Therefore, the results cannot be generalised to broader population groups. However, we have no reason to believe that the detected relationships would be substantially different in other Finnish regions where the socioeconomic context is similar to the one described here.

The sample was not sufficient to explore the extent to which abundant parental SC could compensate for the negative impact of the growth environment, or vice versa. Although demanding from the data perspective, these details will be valuable topics for future research.

The parents' sub-sample was strongly dominated by mothers, which impeded, for example, a separate analysis of mothers' and fathers' SC. This would have been relevant, as previous research indicates that mothers' influence in early adolescence is stronger than that of fathers.

Due to the hierarchical structure of the student data, a multilevel analysis would have been a sensible methodological choice, but the limited number of clusters ( 21 schools) did not enable this approach (see Maas \& Hox, 2005). However, the intra-class correlations (ICC) of all variables related to adolescents' SC were checked, and those 
with ICC-values above $10 \%$ were omitted from the analysis ${ }^{11}$. This eliminated some otherwise relevant measures of weaker social ties.

Despite the cross-sectional data, a strong causal assumption is inbuilt in our model. Although we cannot prove causality, we can nevertheless be confident about the direction of the associations; that the socioeconomic status of the family or the neighbourhood is what precedes and assumingly affects adult and adolescent SC. However, we recognise that the relationship between parents and adolescents' SC may be bidirectional.

${ }^{11}$ ICC values above $10 \%$ indicate that multilevel analysis is required for the data (see Byrne, 2012, p. 354). 


\section{References}

Bandura, A. (1982). The self and mechanisms of agency. In J. Suls (Ed.), Psychological perspectives on the self (pp. 3-39). Lawrence Erlbaum Associates, Inc. Publishers.

Bandura, A. (2017). Sosiaalis-kognitiivinen teoria [Social-cognitive theory]. In R. Vasta (Ed.), Kuusi teoriaa lapsen kehityksestä [Six theories on child development] (3rd ed., pp. 13-82). Jessica Kingsley Publishers Ltd.

Bentler, P. M. (1992). On the fit of models to covariances and methodology to the bulletin. Psychological Bulletin, 122(3), 400-404. https://doi.org/10.1037/0033$\underline{2909.112 .3 .400}$

Bourdieu, P. (1986). The forms of capital. In J. E. Richardson (Ed.), Handbook of theory of research for the sociology of education (pp. 241-258). New York: Greenwood Press.

Bourdieu, P. (1990). The logic of practice. Stanford University Press.

Bourdieu, P. (2005). Habitus. In J. Hillier \& E. Rooksby (Eds.), Habitus: A sense of place (pp. 43-51) Ashgate.

Bourdieu, P., \& Wacquant, L. J. D. (1992). An invitation to reflexive sociology. Polity Press.

Byrne, B. M. (2012). Structural equation modeling with mplus: Basic concepts, applications, and programming. Routledge.

Choudhury, S., Blakemore, S. J., \& Charman, T. (2006). Social cognitive development during adolescence. Social Cognitive and Affective Neuroscience, 1(3), 165-174. https://doi.org/10.1093/scan/ns1024

Coleman, J. S. (1988). Social capital in the creation of human capital. American Journal of Sociology, 94, S95-S120. https://doi.org/10.1086/228943 
Coleman, J. S., \& Hoffer, T. (1987). Public and private high schools: the impact of communities. Basic books.

Curran, P. J., West, S. G., \& Finch, J. F. (1996). The robustness of test statistics to nonnormality and specification error in confirmatory factor analysis. Psychological Methods, 1(1), 16-29. https://doi.org/10.1037/1082-989x.1.1.16

Davis, A. N., \& Carlo, G. (2019). The interplay of economic stress and mothers' use of rewards and the relations to prosocial behaviors in low-income adolescents. Journal of Social and Personal Relationships, 36(11-12), 3429-3447. https://doi.org/10.1177/0265407518824156

Elliott, D. S., Wilson, W. J., Huizinga, D., Sampson, R. J., Elliott, A., \& Rankin, B. (1996). The effects of neighborhood disadvantage on adolescent development. Journal of Research in Crime and Delinquency, 33(4), 389-426. https://doi.org/10.1177/0022427896033004002

Engbers, T. A., Thompson, M. F., \& Slaper, T. F. (2017). Theory and measurement in social capital research. Social Indicators Research, 132(2), 537-558. https://doi.org/10.1007/s11205-016-1299-0

Erola, J. (2010). Yhteiskuntaluokat, tulot ja lasten määrä [Social class, income, and the number of children]. In J. Erola (Ed.), Luokaton suomi? Yhteiskuntaluokat 2000luvun suomessa [Classless Finland? Social classes in Finland in the 2000s] (pp. 89-106). Gaudeamus.

Ferguson, K. M. (2006). Social capital and children's wellbeing: A critical synthesis of the international social capital literature. International Journal of Social Welfare, $15,2-18$. 
Fett, A. K., Gromann, P. M., Giampietro, V., Shergill, S. S., \& Krabbendam, L. (2014a). Default distrust? an fMRI investigation of the neural development of trust and cooperation. Social Cognitive and Affective Neuroscience, 9(4), 395-402. https://doi.org/10.1093/scan/nss144

Fett, A. K., Shergill, S. S., Gromann, P. M., Dumontheil, I., Blakemore, S. J., Yakub, F., \& Krabbendam, L. (2014b). Trust and social reciprocity in adolescence-A matter of perspective-taking. Journal of Adolescence, 37(2), 175-184. https://doi.org/10.1016/j.adolescence.2013.11.011

Field, A. (2009). Discovering statistics using SPSS (and sex, drugs and rock'n'roll).

\section{SAGE.}

Granovetter, M. S. (1973). The strength of weak ties. American Journal of Sociology, 78(6), 1360-1380. https://doi.org/10.1086/225469

Hair, J., Anderson, R., Tatham, R., \& Black, W. (2010). Multivariate data analysis (7th ed.). Prentice-Hall.

Hjalmarsson, S., \& Mood, C. (2015). Do poorer youth have fewer friends? the role of household and child economic resources in adolescent school-class friendships. Children and Youth Services Review, 57, 201-211. https://doi.org/10.1016/j.childyouth.2015.08.013

Hu, L., \& Bentler, P. M. (1995). Evaluating model fit. In R. H. Hoyle (Ed.), Structural equation modeling, concepts, issues, and applications (pp. 76-79). SAGE.

Hu, L., \& Bentler, P. M. (1998). Fit indices in covariance structure modeling: Sensitivity to underparameterized model misspecification. Psychological Methods, 3(4), 424-453. https://doi.org/10.1037/1082-989X.3.4.424 
Jonsson, J., \& Mood, C. (2014). Sociala konsekvenser av ekonomisk utsatthet. Umgänge, stöd och deltagande [Social consequences of economic vulnerability. Company, support and participation]. In M. Evertsson \& C. Magnusson (Eds.), Ojämlikhetens dimensioner. Uppväxtvillkor, arbete och hälsa i Sverige [Dimensions of inequality. Childhood conditions, work and health in Sweden]. Liber.

Kline, R. B. (2011). Principles and practice of structural equation modeling (3rd ed.). Guilford Press.

Kouvo, A. (2010). Luokat ja sosiaalinen pääoma [Classes and social capital]. In J. Erola (Ed.), Luokaton Suomi? Yhteiskuntaluokat 2000-luvun suomessa [Classless Finland? Social classes in Finland in the 2000s] (pp. 166-181). Gaudeamus. Laurence, J. (2019). Community disadvantage, inequalities in adolescent subjective well-being, and local social relations: The role of positive and negative social interactions. Social Science and Medicine, 237. https://doi.org/10.1016/j.socscimed.2019.112442

Lin, N. (2001). Social capital: A theory of social structure and action. Cambridge University Press.

Lindfors, P., Minkkinen, J., Rimpelä, A., \& Hotulainen, R. (2018). Family and school social capital, school burnout and academic achievement: A multilevel longitudinal analysis among Finnish pupils. International Journal of Adolescence and Youth, 23(3), 368-381. https://doi.org/10.1080/02673843.2017.1389758

Maas, C. J. M., \& Hox, J. J. (2005). Sufficient sample sizes for multilevel modeling. Methodology, 1(3), 86-92. https://doi.org/10.1027/1614-2241.1.3.86 
McGinley, M., Carlo, G., Crockett, L. J., Raffaelli, M., Stone, R. A., \& Iturbide, M. I. (2010). Stressed and helping: The relations among acculturative stress, gender, and prosocial tendencies in Mexican Americans. Journal of Social Psychology, 150(1), 34-56. https://doi.org/10.1080/00224540903365323

Moen, P., Erickson, M. A., \& Dempster-Mcclain, D. (1997). Their mother's daughters? the intergenerational transmission of gender attitudes in a world of changing roles. Journal of Marriage and the Family, 59(2), 281-293.

https://doi.org/10.2307/353470

Muthén, L. K., \& Muthén, B. O. (2006). Mplus users' guide (4th ed.). Muthén \& Muthén.

Nomaguchi, K. M., Giordano, P. C., Manning, W. D., \& Longmore, M. A. (2011). Adolescents' gender mistrust: Variations and implications for the quality of romantic relationships. Journal of Marriage and the Family, 73(5), 1032-1047. https://doi.org/10.1111/j.1741-3737.2011.00855.x

Novak, D., Emeljanovas, A., Mieziene, B., Štefan, L., \& Kawachi, I. (2018). How different contexts of social capital are associated with self-rated health among Lithuanian high-school students. Global Health Action, 11(1). https://doi.org/10.1080/16549716.2018.1477470

Organization for Economic Co-Operation and Development (OECD). (2019). Society at a glance 2019. OECD social indicators. OECD Publishing.

Padilla-Walker, L. M., Carlo, G., \& Memmott-Elison, M. K. (2018). Longitudinal change in adolescents' prosocial behavior toward strangers, friends, and family. Journal of Research on Adolescence, 28(3), 698-710.

https://doi.org/10.1111/jora.12362 
Pichler, F., \& Wallace, C. (2009). Social capital and social class in Europe: The role of social networks in social stratification. European Sociological Review, 25(3), 319332. https://doi.org/10.1093/esr/jen050

Putnam, R. D. (2000). Bowling alone: The collapse and revival of American community. Simon \& Schuster.

Ross, C. E., Mirowsky, J., \& Pribesh, S. (2001). Powerlessness and the amplification of threat: Neighborhood disadvantage, disorder, and mistrust. American Sociological Review, 66(4), 568-591. https://doi.org/10.2307/3088923

Rotenberg, K. J. (1995). The socialisation of trust: Parents' and children's interpersonal trust. International Journal of Behavioral Development, 18(4), 713-726. https://doi.org/10.1177/016502549501800408

Sampson, R. J., \& Groves, W. B. (1989). Community structure and crime: Testing social-disorganization theory. American Journal of Sociology, 94(4), 774-802. https://doi.org/10.1086/229068

Sampson, R. J. (2012). Great American city: Chicago and the enduring neighborhood effect. University of Chicago Press.

Stamos, A., Altsitsiadis, E., \& Dewitte, S. (2019). Investigating the effect of childhood socioeconomic background on interpersonal trust: Lower childhood socioeconomic status predicts lower levels of trust. Personality and Individual Differences, 145, 19-25. https://doi.org/10.1016/j.paid.2019.03.011

Stolle, D., \& Hooghe, M. (2004). The roots of social capital: Attitudinal and network mechanisms in the relation between youth and adult indicators of social capital. Acta Politica, 39(4), 422-441. https://doi.org/10.1057/palgrave.ap.5500081 
Stolle, D., \& Nishikawa, L. (2011). Trusting others-How parents shape the generalized trust of their children. Comparative Sociology, 10(2), 281-314. https://doi.org/10.1163/156913311x566599

Sutter, M., \& Kocher, M. G. (2007). Trust and trustworthiness across different age groups. Games and Economic Behavior, 59(2), 364-382. https://doi.org/10.1016/j.geb.2006.07.006

Tuominen, M., \& Haanpää, L. (2021). Young people's well-being and the association with social capital, i.e. Social Networks, Trust and Reciprocity. Social Indicators Research, 1-29. https://doi.org/10.1007/s11205-021-02762-z

Valdimarsdóttir, M., \& Bernburg, J. G. (2015). Community disadvantage, parental network, and commitment to social norms. Journal of Research in Crime and Delinquency, 52(2), 213-244. https://doi.org/10.1177/0022427814548685

Veysey, B. M., \& Messner, S. F. (1999). Further testing of social disorganization theory: An elaboration of Sampson and Groves's “Community structure and crime". Journal of Research in Crime and Delinquency, 36(2), 156-174. https://doi.org/10.1177/0022427899036002002

Weiss, H. E. (2012). The intergenerational transmission of social capital: A developmental approach to adolescent social capital formation. Sociological Inquiry, 82(2), 212-235. https://doi.org/10.1111/j.1475-682x.2012.00414.x

Wooldridge, J. M. (2018). Introductory Econometrics: A Modern Approach (6th ed.). Boston: Cengage Learning. 


\section{Data references}

[dataset] European Social Survey Round 6 Data, (2012). NSD - Norwegian Centre for

Research Data, Norway - Data Archive and distributor of ESS data for ESS ERIC. Data file edition 2.4. doi:10.21338/NSD-ESS6-2012.

[dataset] Tuominen Minna; 2018; Social capital of children and adults 2018 [Lasten ja aikuisten sosiaalinen pääoma 2018; Finnish Social Science Data Archice; forthcoming. 